\title{
ESCLEROSE SISTÊMICA NEFROGÊNICA EM PACIENTE DIALÍTICO: UM RELATO DE CASO
}

Agnes Gabrielle Wagner ${ }^{1}$, Ana Claudia Kurmann ${ }^{1}$, Fabiana Piovesan ${ }^{2,3}$

\section{INTRODUÇÃO}

Esclerose Sistêmica Nefrogênica (ESN) é uma desordem fibrótica sistêmica e grave, geralmente progressiva, debilitante e potencialmente fatal, que ocorre exclusivamente em pacientes com disfunção renal prévia. É caracterizada por espessamento e endurecimento da pele que recobre as extremidades e tronco e fibrose de músculo esquelético, articulações, fígado pulmão e/ou coração. Embora a causa da ESN ainda seja desconhecida, tem sido sugerida sua relação com os contrastes à base de Gadolínio, havendo um risco de aproximadamente $4,2 \%$ para cada exposição.

\section{OBJETIVOS}

O presente relato visa descrever o caso de esclerose sistêmica nefrogênica em paciente com Insuficiência Renal Crônica (IRC) em hemodiálise com histórico de exposição à contraste à base de Gadolínio, bem como sua evolução e conduta.

\section{RELATO DO CASO}

Paciente masculino, 45 anos, doente renal crônico secundário à gromerulonefrite pós-estreptococóccia há 12 anos, em hemodiálise há 8 anos, inicia com queixas de dor intensa em regiões de infiltração da derme há 4 meses. O quadro é acompanhado de ageusia, esclerodactilia, perda da mobilidade de pernas e pés, disfagia para sólidos e líquidos, disfonia e perda ponderal de $18 \mathrm{~kg}$, com necessidade de alimentação via sonda nasogástrica. Além disso, o paciente tem histórico de meningeoma há 12 anos - com intensa exposição à contraste contendo Gadolínio durante a investigação diagnóstica com subsequentes ressonâncias magnéticas de crânio -, cirrose por vírus $\mathrm{B}$ e amiloidose. Após ampla investigação, o paciente foi diagnosticado com ESN, presumivelmente secundária à exposição prévia à contraste contendo Gadolínio. Iniciou-se esquema terapêutico multimodal, envolvendo terapia medicamentosa e fisioterapia. $O$ paciente seguiu com a terapia de substituição renal e acompanhamento com a equipe da nefrologia, sem apresentar maiores complicações. Atualmente, necessita de cadeira de rodas para a locomoção, devido à rigidez dos membros inferiores.
1 Acadêmica de Medicina da Universidade de Passo Fundo 2 Professora de Sistema Genito-urinário da Universidade de Passo Fundo ${ }^{3}$ Médica Nefrologista do Hospital São Vicente de Paulo

\section{CONCLUSÃO}

Apesar de ainda existirem importantes lacunas a serem preenchidas sobre a ESN, sabe-se que são quadros de rápida evolução e alta mortalidade. Assim, ratifica-se a importância do acompanhamento de doentes renais crônicos em hemodiálise, sempre considerando a ESN uma possível comorbidade em desenvolvimento. Além disso, visto que a maioria dos casos relatados estão associados à exposição ao Gadolínio, evitá-lo em pacientes com insuficiência renal avançada é a principal medida preventiva.

\section{REFERENCIAS}

1. Amet S, Launay-Vacher V, Clément $\mathrm{O}$, et al. Incidence of nephrogenic systemic fibrosis in patients undergoing dialysis after contrast-enhanced magnetic resonance imaging with gadolinium-based contrast agents: the Prospective Fibrose Nephrogénique Systémique study. Invest Radiol 2014; 49:109.

2. LEITE, Claudia da Costa. Fibrose nefrogênica sistêmica: novas diretrizes. Radiol Bras, São Paulo , v. 43, n. 2, p. V-VI, Apr. 2010 .

3. MUNDIM, Juliano Sacramento et al . Fibrose sistêmica nefrogênica: uma complicação grave do uso do gadolínio em pacientes com insuficiência renal. Rev. Assoc. Med. Bras., São Paulo, v. 55, n. 2, p. 220-225, 2009

\section{ANEXOS}
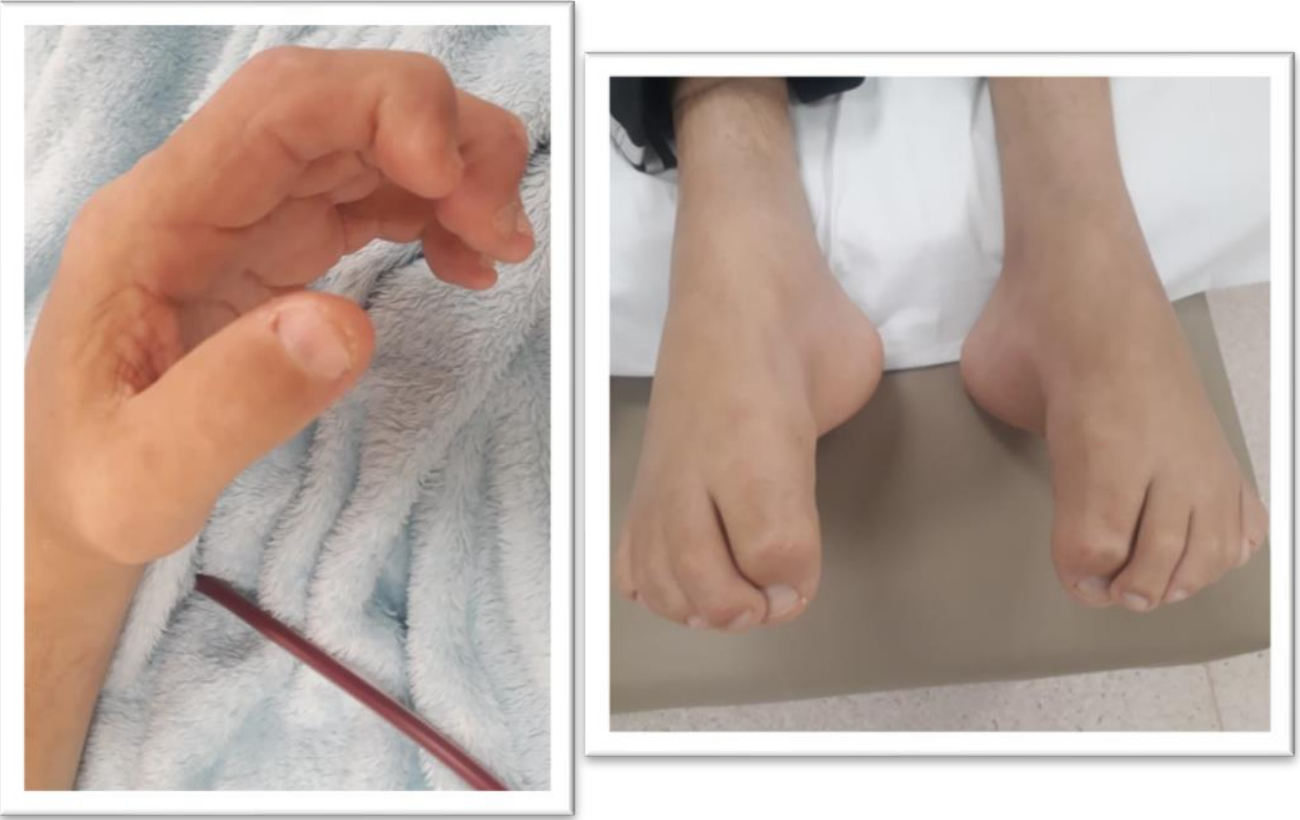